\title{
Short-Term and Long-Term Survival of New Neurons in the Rat Dentate Gyrus
}

\author{
ALEXANDRE G. DAYER, ${ }^{*}$ ABIGAIL A. FORD, KATHRYN M. ClEAVER, \\ MINA YASSAEE, AND HEATHER A. CAMERON \\ Unit on Neuroplasticity, Mood and Anxiety Disorders Program, National Institute of \\ Mental Health, National Institutes of Health, Department of Health and Human Services, \\ Bethesda, Maryland 20892
}

\begin{abstract}
New neurons continue to be generated in the dentate gyrus throughout adulthood. Previous studies have shown that a significant proportion of new granule cells labeled with the thymidine analogue bromodeoxyuridine (BrdU) are lost from the adult dentate gyrus within 2 weeks. How long this loss continues and the extent to which it represents cell death, as opposed to dilution of label, is unclear. To address these questions, adult rats were injected with BrdU, and BrdU labeling in the dentate gyrus was compared at several survival time points. Double labeling with BrdU and the cell cycle marker Ki-67 showed that BrdU is detectable for up to 4 days in some cells that continue to divide, indicating that any decrease in the number of BrdU-labeled cells after 4 days is likely to reflect cell death rather than BrdU dilution. Death of new cells in the granule cell layer occurred at a steady rate between 6 and 28 days after labeling, resulting in loss of 50\% of BrdU-labeled cells over this 22-day period. New granule cells that survived this first month lived for at least 5 additional months. In contrast, $26 \%$ of the granule cells labeled with BrdU at the peak of dentate gyrus development on postnatal day (P) 6 died between 1 and 6 months after labeling. These findings suggest that granule cells born during adulthood that become integrated into circuits and survive to maturity are very stable and may permanently replace granule cells born during development. J. Comp. Neurol. 460:563-572, 2003. Published 2003 Wiley-Liss, Inc. ${ }^{\dagger}$
\end{abstract}

Indexing terms: cell cycle; cell death; bromodeoxyuridine; hippocampus; adult neurogenesis development

The dentate gyrus produces new granule neurons throughout adulthood in mammals from rodents to humans (Gould and Gross, 2002). The initial generation of new cells through proliferation of immature precursor cells is regulated by a wide variety of factors (Eisch and Nestler, 2002), but a large number of new cells are generated in the normal adult dentate gyrus-as many as 9,000 per day in a young adult rat (Cameron and McKay, 2001). Many of these newborn cells differentiate into granule neurons (Cameron et al., 1993) and survive for at least 8 months in rodents (Altman and Das, 1965), 12 weeks in the macaque (Gould et al., 2001), and 2 years in humans (Eriksson et al., 1998). However, previous studies have suggested that a large proportion of new cells may die before reaching maturity. Small numbers of pyknotic or TUNEL-stained dying cells can be observed in the normal adult dentate gyrus (Gould et al., 1990; Biebl et al., 2000). Although the age and identity of the dying cells has not been examined, the location of many of the pyknotic cells at the border of the granule cell layer with the hilus

PUBLISHED 2003 WILEY-LISS, INC. 'This article is a US Government work and, as such, is in the public domain in the United States of America.
(Gould et al., 1990) suggests that they are newly born neurons. Additional indirect evidence for death of new neurons has come from studies showing a decrease in the number of new cells in the adult dentate gyrus between 1 week and 2 weeks after they are labeled with bromodeoxyuridine (BrdU) or $\left[{ }^{3} \mathrm{H}\right]$ thymidine (Cameron et al., 1993; Gould et al., 1999). Although it is not clear from the early study whether this decrease was due to death of newborn cells or dilution of the label through continued

Grant sponsor: National Institute of Mental Health Intramural Research Program; Grant sponsor: Swiss National Research Fund.

*Correspondence to: Alexandre G. Dayer, National Institutes of Health, Building 36/3D26 MSC 4027, Bethesda, MD 20892

E-mail: dayera@intra.nimh.nih.gov

Received 26 November 2002; Revised 21 January 2003; Accepted 28 January 2003

DOI 10.1002/cne.10675

Published online the week of April 21, 2003 in Wiley InterScience (www. interscience.wiley.com). 
cell division, the significant inhibition of cell loss in rats engaging in hippocampus-dependent learning tasks in the later study strongly suggests that newborn cells are dying (Gould et al., 1999). The accompanying decrease in the number of pyknotic, or dying, cells in rats given learning tasks further supports this idea (Gould et al., 1999).

Despite the great interest in new neurons in the adult dentate gyrus, we still have very little information regarding their normal rate of cell death at different stages of neuronal differentiation and maturation. For example, it is not known when loss of BrdU-labeled cells due to label dilution, which is indistinguishable from cell death, begins or ends. And although cell death appears to occur at a fairly high rate in cells between 1 and 2 weeks after BrdU labeling, it is not known whether cells are particularly susceptible to cell death on one particular day or throughout this period. The seemingly rapid cell death during this 1 -week period can be taken as evidence that neurons born in adulthood do not live very long (e.g. Madsen et al., 2000 ), but it is not known whether this high rate of cell death continues, resulting in a short lifespan for adultborn granule neurons. Little is known about the lifespan of granule cells born during development either. Some of the granule neurons born during the peak of development in the first postnatal week (Schlessinger et al., 1975; Bayer, 1980a, b; Gould et al., 1991) survive for at least 16 months (Crespo et al., 1986), but whether this is a rare or common occurrence is unknown.

To address these questions, we used the S-phase marker BrdU to label newly born cells in the dentate gyrus of adult rats and compared the numbers of BrdU-labeled cells at several time points after labeling. Additionally, we compared the long-term survival rate of granule cells born in adulthood to that of granule cells born during the peak of developmental granule cell birth, during the first postnatal week.

\section{MATERIALS AND METHODS Animal treatments}

For the developmental injection experiment, pregnant Sprague-Dawley rat dams (embryonic day [E] 16) were purchased from Taconic Farms (Germantown, NY). On postnatal day (P) 3 (2 days after birth), pups were pooled, and four males and four females were randomly distributed to each dam. One dam with litter was housed per cage until weaning (P28), at which time male pups were housed like adult rats in the other experiments. Adult male Sprague-Dawley rats (300-350 g, 8-9 weeks old) were purchased from Charles River (Wilmington, MA; 16 to 28-day survival experiment) or Taconic Farms (all other experiments). Adult rats in all experiments were housed two per cage throughout the experiment, except when their weight exceeded $400 \mathrm{~g}$ (at 13 weeks old). Rats were maintained on a 12:12 light:dark cycle and provided with unlimited access to food and water for the duration of each experiment.

Each rat received a single i.p. injection of $\mathrm{BrdU}$ (300 $\mathrm{mg} / \mathrm{kg}, 10 \mathrm{mg} / \mathrm{ml}$ in $0.007 \mathrm{~N} \mathrm{NaOH} / 0.9 \% \mathrm{NaCl}$; Boehringer Mannheim, Indianapolis, IN) either on P6 (male and female pups were injected, but only males were used in the experiment) or at 8-9 weeks of age. All rats within a given experiment were injected at the same time. Experiments with different survival times were conducted on different
TABLE 1. Summary of Experiments ${ }^{1}$

\begin{tabular}{ll}
\hline Age at injection & Survival time after BrdU injection \\
\hline $8-9$ weeks old (adult) & $0 \mathrm{~d}(2 \mathrm{~h})^{*}, 1 \mathrm{~d}^{*}, 2 \mathrm{~d}^{*}, 3 \mathrm{~d}^{*}, 4 \mathrm{~d}^{*}$ \\
$8-9$ weeks old (adult) & $6 \mathrm{~d}, 8 \mathrm{~d}, 10 \mathrm{~d}, 12 \mathrm{~d}, 14 \mathrm{~d}, 16 \mathrm{~d}^{*}$ \\
$8-9$ weeks old (adult) & $16 \mathrm{~d}, 20 \mathrm{~d}, 24 \mathrm{~d}, 28 \mathrm{~d}$ \\
$8-9$ weeks old (adult) & $1 \mathrm{~m}(28 \mathrm{~d}) \dagger, 2 \mathrm{~m}, 3 \mathrm{~m}, 4 \mathrm{~m}, 5 \mathrm{~m}, 6 \mathrm{~m}(168 \mathrm{~d}) \dagger$ \\
P6 (peak of development) & $1 \mathrm{~m}(28 \mathrm{~d}), 2 \mathrm{~m}, 3 \mathrm{~m}, 4 \mathrm{~m}, 5 \mathrm{~m}, 6 \mathrm{~m}(168 \mathrm{~d})$ \\
\hline${ }^{1} \mathrm{~h}$, hour; d, day; w, week; m, month; BrdU, bromodeoxyuridine. Asterisks indicate \\
group used for BrdU/Ki-67 double labeling; daggers indicate group used for BrdU/NeuN \\
double labeling.
\end{tabular}

days; the adult and developmental 1- to 6-month survival experiments were conducted simultaneously. Rats were deeply anesthetized with isoflurane inhalation and transcardially perfused with $4 \%$ paraformaldehyde $(\mathrm{pH} 7.4)$ at different intervals after BrdU injection (see Table 1). In all experiments, four rats were killed at each survival time point, except at 20 days $(n=3)$ and at 24 days $(n=5)$. All animal treatments conformed to NIH guidelines and were approved by the NIMH Institutional Animal Care and Use Committee.

\section{Tissue processing}

Brains from all experiments were dissected from the skulls, post-fixed overnight in $4 \%$ paraformaldehyde $(\mathrm{pH}$ 7.4 ), then cryoprotected in $20 \%$ sucrose. Coronal sections $(50 \mu \mathrm{m})$ through the entire dentate gyrus were cut on a freezing microtome. Series of every 12th section through each brain were processed for BrdU immunohistochemistry with diaminobenzidine (DAB), according to a previously published protocol (Cameron and McKay, 2001). Briefly, sections were mounted on slides, heated in citric acid (0.1 M, pH 6.0) for 10 minutes for antigen retrieval, permeabilized with trypsin for 10 minutes, and denatured in $2 \mathrm{~N} \mathrm{HCl}$ for 30 minutes. Staining then followed standard immunohistochemical staining procedures using monoclonal mouse anti-BrdU antibody (1:100; BectonDickinson, San Jose, CA) at $4^{\circ} \mathrm{C}$ overnight, biotinylated goat anti-mouse immunoglobulin G (1:200; Sigma, St. Louis, MO) at room temperature for 1 hour, an avidinbiotin-peroxidase kit (Vector Laboratories, Burlingame, CA) and cobalt-enhanced DAB (Sigma Fast tablets). Immunohistochemistry was performed simultaneously on series from all rats within a given experiment to maximize the reliability of comparison across groups. All sections were counterstained with cresyl violet and cover-slipped under Permount.

For immunofluorescent staining, series of every 24th section from some rats (see Table 1) were processed for simultaneous BrdU/Ki-67 or BrdU/NeuN double labeling as follows. Free-floating $50-\mu \mathrm{m}$ sections were pretreated with $2 \mathrm{~N} \mathrm{HCl}$ for 30 minutes, incubated overnight either with monoclonal mouse anti-BrdU antibody (1:100; Becton-Dickinson) and polyclonal rabbit anti-Ki-67 (1:1,000; Novocastra Labs, Newcastle upon Tyne, United Kingdom), or with monoclonal rat anti-BrdU (1:100; Accurate, Westbury, NY) and monoclonal mouse anti-NeuN (Chemicon, 1:250). Sections were then incubated for 1 hour with Alexa 488-conjugated and Alexa 568conjugated secondary antibodies against the appropriate species (1:250; Molecular Probes, Eugene, OR) counterstained with Hoechst 33258, and cover-slipped under $70 \%$ glycerol. 


\section{Data analysis}

In all sections processed for BrdU immunohistochemistry alone, BrdU-labeled cells were estimated by using stereologic methods, as previously described (Cameron and McKay, 2001). Specifically, BrdU-labeled cells in the granule cell layer (gcl) and hilus of every 12th DABstained section through the entire bilateral dentate gyrus were counted at $400 \times$ on coded slides. For the 0 - to 4 -day survival experiment, cells in the subgranular zone (within two cell body widths of the gcl) were counted as part of the gcl so that clusters of labeled cells were not split between the gcl and hilus. For all other experiments (those with survival times longer than 4 days), only labeled cells touching other cells in the gcl were counted as belonging to the gcl, as in previous studies (Cameron et al., 1993; Cameron and McKay, 2001). For each brain, the total number of BrdU-labeled cells was estimated by multiplying the number of cells counted by 12 . Each experiment was analyzed by two investigators, with each investigator counting a half-series (every 24th section). During the analysis, one brain at each of four different time points (8 and 16 days from the 6- to 16-day survival experiment and 1 and 3 months from the adult 1- to 6-month experiment) had very poor BrdU labeling and was excluded from the analysis. Data were subjected to linear regression analysis or analysis of variance with Fisher protected least significant difference post hoc tests (Statview 4.5).

In fluorescently double-labeled sections, BrdU-labeled cells in the gcl and hilus were counted and categorized as immunoreactive or nonimmunoreactive for $\mathrm{NeuN}$ or $\mathrm{Ki}-67$ by using an Olympus epifluorescent microscope with $\mathrm{Al}$ exa 488 and 568 filters. Percentages of double-labeled cells were then calculated for each brain. For Ki-67-BrdU double labeling, a total of 344 and 291 BrdU-labeled cells at 2 hours, 474 and 354 cells at 1 day, 613 and 428 cells at 2 days, 558 and 469 cells at 3 days, 695 and 459 cells at 4 days, 258 and 151 at 8 days, and 197 and 126 at 16 days were counted in the gcl and hilus, respectively. For NeuN, a total of 244 BrdU-labeled cells at 1 month and 230 BrdU-labeled cells at 6 months were counted in the gcl. No BrdU-NeuN-positive cells were observed in the hilus on any section at either time point. Fluorescent images were collected using a Zeiss 510 confocal microscope. Brightfield images were collected by using a Zeiss Axiocam HR color digital camera run by Openlab software (Improvision) on an Olympus BX51 microscope. Photomicrographs were arranged and adjusted for brightness and contrast in Adobe Photoshop.

\section{RESULTS \\ Cells labeled in adulthood: 2-hour to 4-day survival}

To determine how long dividing cells continue to be visibly BrdU-labeled before the label is diluted below the limits of detection, we immunohistochemically stained sections for BrdU and $\mathrm{Ki}-67$, a marker that is expressed by cells in all phases of the cell cycle with the possible exception of early G1 (Scholzen and Gerdes, 2000). BrdUlabeled and Ki-67-labeled cells were observed in all sections analyzed. Their general distribution in the dentate gyrus was very similar, with the two markers frequently appearing in the same cell (Fig. 1). Over the 4-day interval, the percentage of BrdU-labeled cells in the gcl that
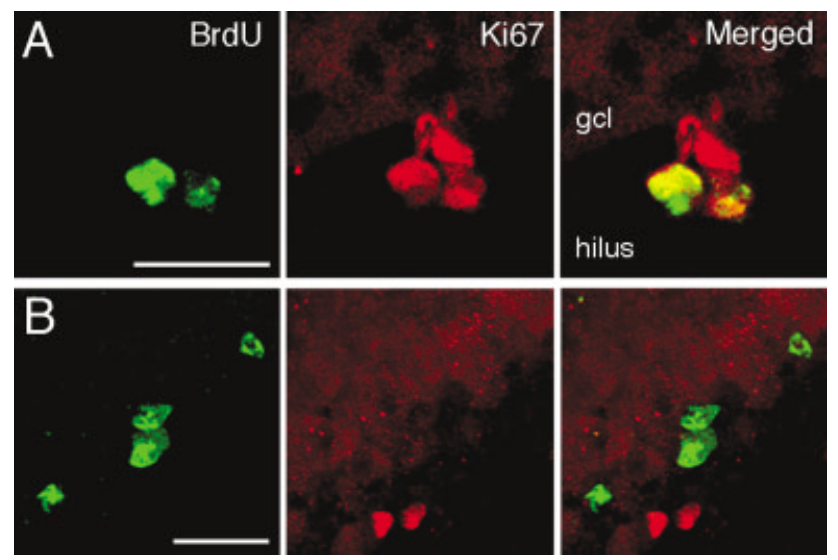

Fig. 1. Confocal images of bromodeoxyuridine (BrdU) and Ki-67 staining. A: A cluster of cells on the border of the granule cell layer (gcl) and hilus 2 hours after BrdU injection contains double-labeled cells as well as cells labeled with Ki-67 alone. Projection image of three confocal planes with a total depth of $2.8 \mu \mathrm{m}$. B: Four days after BrdU injection, BrdU-labeled cells are located within the gcl and do not express Ki-67, whereas Ki-67-labeled cells are in the subgranular zone and are not labeled with BrdU. Projection image of 10 confocal planes with a total depth of $6.7 \mu \mathrm{m}$. Scale bars $=20 \mu \mathrm{m}$ in A,B.

were double-labeled with Ki-67 progressively decreased from $91.4 \pm 4.9 \%$ at 2 hours to $4.0 \pm 1.3 \%$ at 4 days (Fig. $2 \mathrm{~A})$. In the hilus, only $72 \pm 3.3 \%$ of BrdU-labeled cells were Ki-67-positive 2 hours after BrdU injection, and BrdU/Ki-67 coexpression dropped very rapidly, reaching $7.0 \pm 3.1 \% 24$ hours after BrdU injection.

In sections immunostained for BrdU alone using DAB, BrdU-labeled cells were observed primarily on the border of the gcl and hilus. At later time points, BrdU-labeled cells were frequently found in large clusters. Between 2 hours and 1 day after BrdU injection, the number of BrdUlabeled cells in the dentate gyrus (gcl plus hilus) increased 1.7-fold (Fig. 2B). The increase was significant $(P<0.05)$ and of a similar magnitude in the gcl $(1.68 \times)$ and the hilus $(1.75 \times)$. After the initial increase between 2 and 24 hours, the number of BrdU-labeled cells did not change significantly $(P>0.1$ by linear regression) over the next 3 days (Fig. 2B) in either region. BrdU-labeled pyknotic cells were rare but were observed at every survival time except 2 hours after injection (Fig. 3).

\section{Cells labeled in adulthood: 6- to 16-day survival}

BrdU-labeled cells in this experiment were generally not found in clusters but were instead spread out along the edge of the gcl. Many of the cells had a punctate pattern of BrdU staining. Regression analysis showed a significant linear decrease $(P<0.05)$ of approximately $178 \pm 66$ BrdU-labeled cells per day in the gcl between 6 and 16 days after BrdU injection (Fig. 4A; Table 2), resulting in a $29 \%$ loss over the 10 -day period. The rate of cell loss appeared constant across this period. The number of BrdU-labeled cells in the hilus showed no significant change $(P>0.1$; Fig. 4B; Table 2$)$.

To exclude the possibility that a decrease in BrdUlabeled cells during this period could be caused by label dilution due to renewed proliferation in BrdU-labeled immature neurons, we double-stained sections from 8-day 


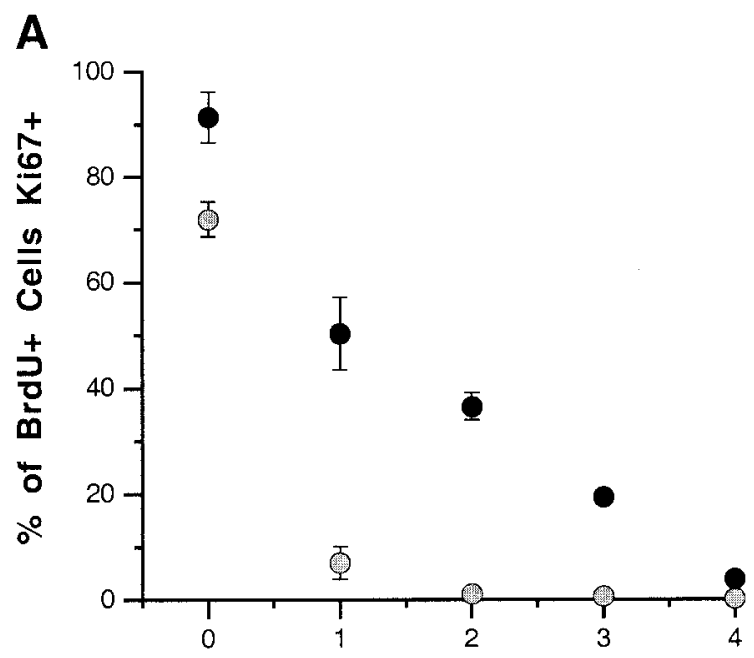

Time After BrdU Injection (days)

B

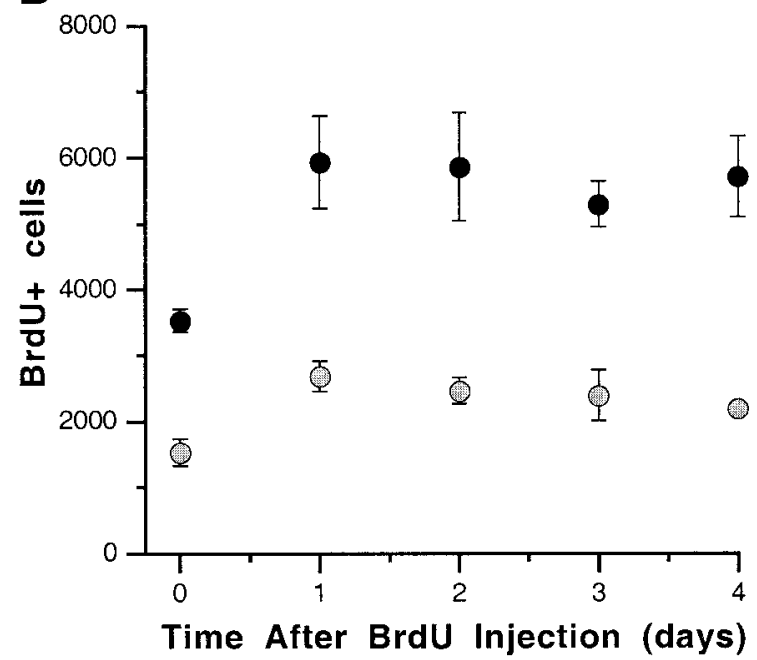

Fig. 2. Bromodeoxyuridine (BrdU) is diluted below the limits of detection over 4 days in cells that continue to divide. A: The proportion of BrdU-labeled cells that are Ki-67 immunoreactive in the granule cell layer (gcl; black) and hilus (gray). In the gcl, all time points are significantly different from each other. In the hilus, the 0 day ( 2 hour) time point is significantly different from all others, and the 1 day time point is significantly different from the 4 day time point. B: The total number (bilateral) of BrdU-labeled cells in the gcl (black) and hilus (gray). The 2-hour time point is significantly different from all other time points in both gcl and hilus (analysis of variance and Fisher protected least significant difference post hoc tests); no change is apparent between 1 and 4 days (linear regression).

and 16-day time points with BrdU and Ki-67. No doublelabeled cells were found in the gcl at either of these two time points. Surprisingly, in the hilus, 2 double-labeled cells were observed (of 126 BrdU-labeled cells examined) at 16 days after BrdU injection.

\section{Cells labeled in adulthood: 16- to 28-day survival}

Regression analysis showed a significant linear decrease $(P<0.05)$ of approximately $125 \pm 47$ BrdU-labeled

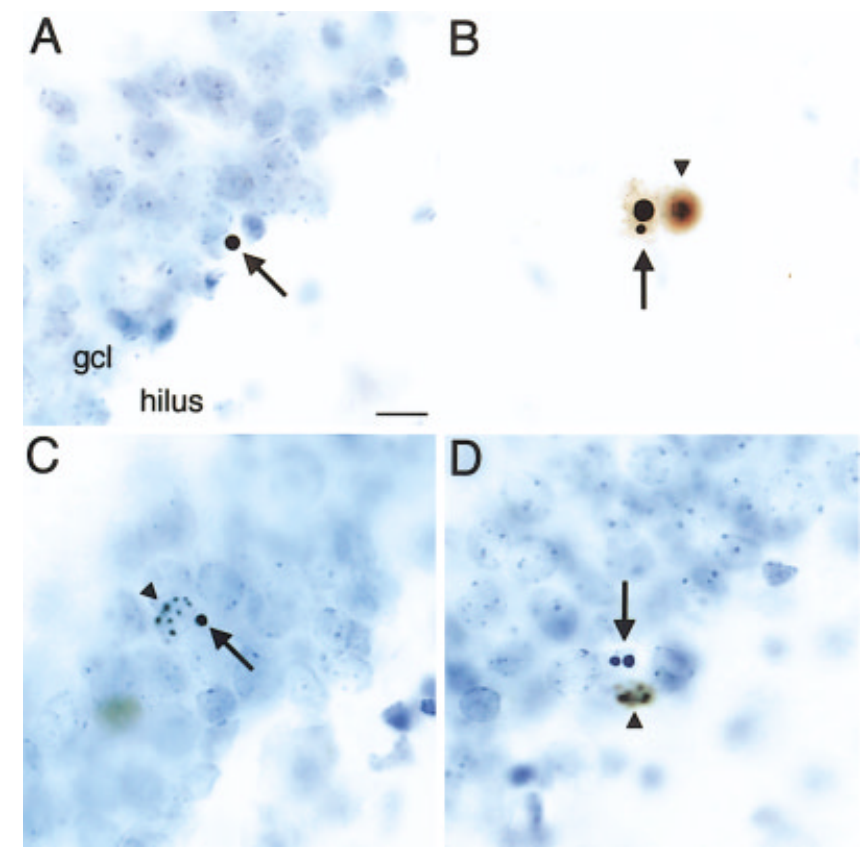

Fig. 3. Examples of pyknotic, or dying, cells in sections immunostained for bromodeoxyuridine (BrdU; brown/black) and counterstained with cresyl violet (blue). A: BrdU-labeled pyknotic cell (arrow) from a rat injected with BrdU 24 hours earlier. The condensed chromatin appears very round and densely black. B: BrdU-labeled pyknotic cell (arrow) 16 days after BrdU injection. A nonpyknotic BrdUlabeled cell in a different plane of focus (arrowhead) can be seen adjacent to the pyknotic cell. C: BrdU-labeled pyknotic cell (arrow) deep in the granule cell layer (gcl) 3 months after BrdU injection at postnatal day (P) 6. A BrdU-labeled nonpyknotic cell (arrowhead) with many more, smaller spots of diaminobenzidine labeling can be seen adjacent to the pyknotic cell. D: BrdU-negative pyknotic cell (arrow) 3 months after BrdU injection at P6. Its condensed chromatin appears very round but is densely blue rather than black. An adjacent nonpyknotic BrdU-labeled cell (arrowhead) appears in a different plane of focus. Scale bar $=10 \mu \mathrm{m}$ in A (applies to A-D).

cells per day in the gcl between 16 and 28 days after BrdU injection (Fig. 4C; Table 2) for a total $27 \%$ decrease. The hilus also showed a significant decrease $(P<0.05)$ across this time period, of approximately $59 \pm 25$ cells per day or $31 \%$ overall (Fig. 4D; Table 2 ). There was no indication in the data that the rate of cell death in the gcl or hilus changed over this period. BrdU-labeled pyknotic cells (Fig. 3) were observed in the dentate gyrus of several brains in this experiment, providing direct evidence for death of BrdU-labeled cells during this period. The number of BrdU-labeled cells 16 days after injection was slightly higher in this experiment than in the previous experiment (6- to 16 -day survival); this difference is likely to reflect random interexperimental variation due to small differences between rats from different vendors or variability in environmental conditions during the experiments.

Together, the 6- to 16-day survival and 16- to 28-day survival experiments suggest a steady decline in the number of 1 - to 4 -week-old cells in the adult gcl. The $29 \%$ loss of cells from 6 to 16 days and the $28 \%$ loss of cells from 16 to 28 days result in an overall decrease of $48 \%$ over this 22 -day period. In the hilus, the nonsignificant early $16 \%$ 

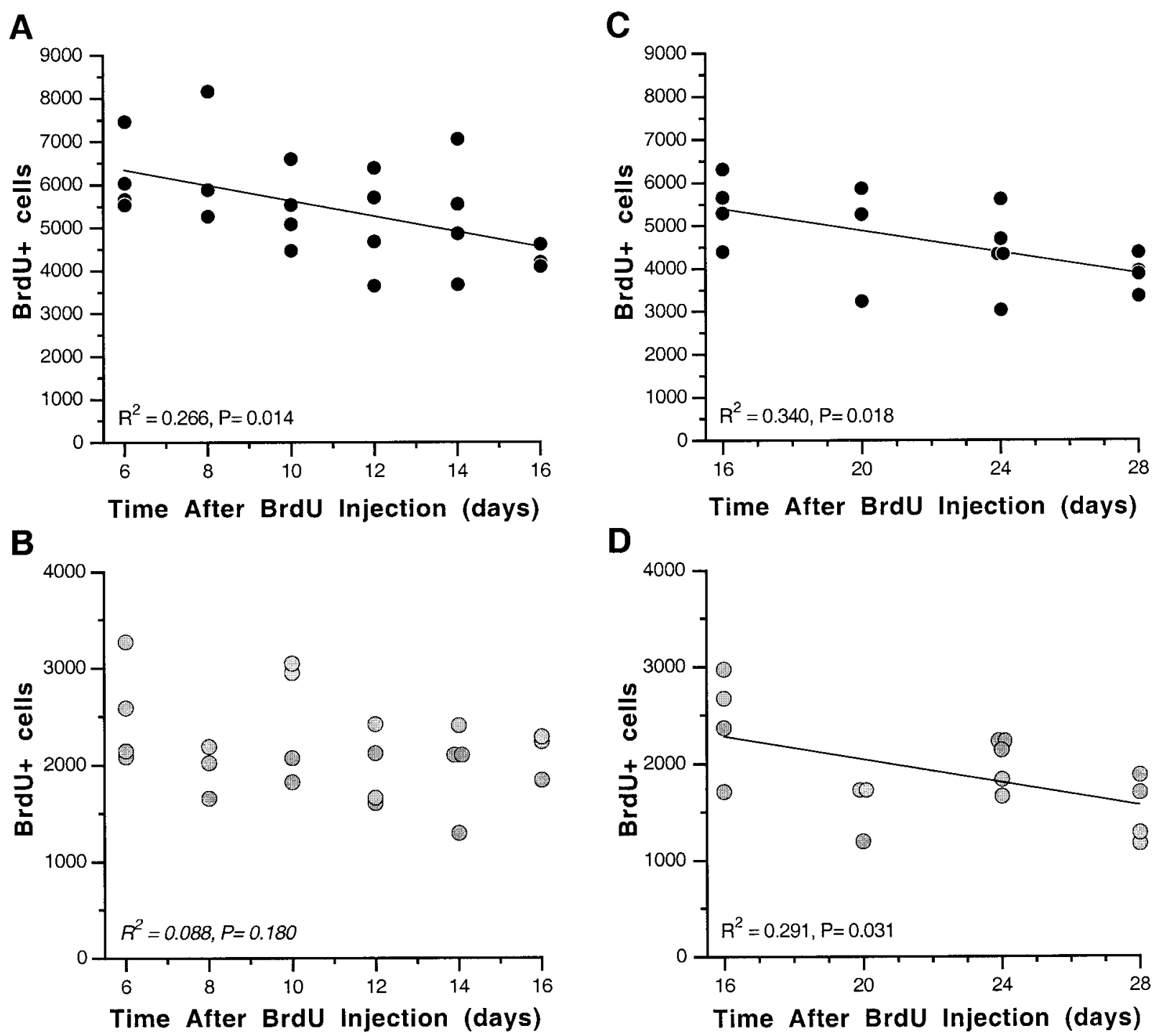

Fig. 4. Cell death occurs throughout the period from 6 to 28 days after bromodeoxyuridine (BrdU) injection. Graphs show the numbers of BrdU-labeled cells in individual rats, with linear regression statistics and regression lines when significant. A: The granule cell layer shows significant loss between 6 and 16 days. B: The hilus does not

loss and the significant later $31 \%$ loss combine to produce a $42 \%$ decrease.

\section{Cells labeled in adulthood: 1- to 6-month survival}

The pattern and location of BrdU-labeled cells in this experiment was similar to that seen in the 16- to 28-day experiment; labeled cells were located predominantly near the hilar border of the granule cell layer even at the longest survival times (Fig. 5). The number of BrdUlabeled cells in the gcl did not change significantly $(P>$ 0.05 ) between 1 and 6 months (Fig. 6A; Table 2). Linear regression did show a trend toward a change across this period $(P=0.093)$. Examination of individual values within this experiment (Fig. $6 \mathrm{~A}$ ) show that one rat in the

show significant cell loss over this period. C: In a separate experiment, the granule cell layer shows significant loss between 16 and 28 days after BrdU injection. D: Cell loss in the hilus is significant during this later period.

2-month group was an outlier, with extremely high BrdU counts $(10,248$ labeled cells), while the remaining points do not suggest a decrease over time. Regression analysis with the outlier removed gives a $P$-value of 0.159 . Taken together, this indicates that there is no change in the number of labeled cells in the gcl over this period.

The number of BrdU-labeled cells in the hilus decreased significantly over this time period $(P<0.001$ by linear regression) with an overall $61 \%$ decrease (Fig. 6B; Table 2 ). Examination of the graph suggests that most of this cell loss occurs between 2 and 4 months after cell birth. The specificity of the cell loss from the hilus is supported by an increase in the proportion of cells located in the gcl from $64 \pm 1 \%$ at 1 month to $77 \pm 3 \%$ at 6 months $(P<$ $0.01)$. 
TABLE 2. Linear Regression Statistics for BrdU-labeled Cell Number at Different Survival Times After BrdU Injection ${ }^{1}$

\begin{tabular}{|c|c|c|c|c|c|}
\hline BrdU injection time & Survival time & Region & $\begin{array}{c}\text { Cell loss/day } \\
\text { (X coefficient) }\end{array}$ & $\mathrm{R}^{2}$ & $P$ value \\
\hline Adulthood (9-10 weeks old) & $\begin{array}{l}\text { 6-16 days } \\
\text { 16-28 days } \\
1-6 \text { months }\end{array}$ & $\begin{array}{l}\text { gcl } \\
\text { hilus } \\
\text { gcl } \\
\text { hilus } \\
\text { gcl } \\
\text { hilus }\end{array}$ & $\begin{aligned}-178 & \pm 66 \\
-41 & \pm 30 \\
-125 & \pm 47 \\
-59 & \pm 25 \\
-7 & \pm 4 \\
-11 & \pm 2\end{aligned}$ & $\begin{array}{l}0.266 \\
0.088 \\
0.340 \\
0.291 \\
0.135 \\
0.713\end{array}$ & $\begin{array}{l}0.014 \\
0.180 \\
0.018 \\
0.031 \\
0.093 \\
0.000\end{array}$ \\
\hline Development (P6) & $1-6$ months & $\begin{array}{l}\text { gcl } \\
\text { hilus }\end{array}$ & $\begin{array}{l}-75 \pm 35 \\
-30 \pm 14\end{array}$ & $\begin{array}{l}0.181 \\
0.186\end{array}$ & $\begin{array}{l}0.043 \\
0.040\end{array}$ \\
\hline
\end{tabular}

${ }_{1}^{1}$ gcl, granule cell layer; BrdU, bromodeoxyuridine. Italics indicate nonsignificant regression.

The percentage of BrdU-labeled cells in the gcl doublelabeled with the mature neuronal marker NeuN was $79.3 \pm 2.6 \%$ at 1 month (Fig. 5), in agreement with previous findings (Biebl et al., 2000; Cameron and McKay, 2001; Nakagawa et al., 2002). At 6 months, $86.6 \pm 3.5 \%$ of the BrdU-labeled cells were double-labeled with NeuN (Fig. 5), a value that is not significantly different from the percentage at 1 month. Together, these findings suggest that within 1 month after becoming postmitotic, cells remaining in the gcl are mature neurons that are very unlikely to die for at least 5 more months.

\section{Cells labeled in development: 1- to 6-month survival}

The pattern of BrdU-labeling was quite different in rats labeled at $\mathrm{P} 6$ than in rats labeled in adulthood. Very large numbers of cells were labeled in these brains relative to those labeled in adulthood, and labeled cells were located throughout the thickness of the gcl, rather than predominantly at the border of the hilus (Fig. 5). One month after BrdU injection, the total number of BrdU-labeled cells in the dentate gyrus was 7.3 times higher in rats injected at P6 (50,752 $\pm 11,990$ cells $)$ than in rats injected in adulthood $(6,944 \pm 165$ cells $)$. In contrast to what was found in young adult rats, the number of newly generated BrdUlabeled cells in the gcl of $\mathrm{P} 6$ pups decreased significantly $(P<0.05)$ at a rate of $2,106 \pm 978$ cells per month, resulting in a total loss of $25 \%$ of the cells over this 5-month period (Fig. 6C; Table 2). Most of this decrease appeared to occur between 2 and 4 months after BrdU injection (Fig. 6C). The number of BrdU-labeled cells in the hilus of $\mathrm{P} 6$ pups also decreased significantly $(P<0.05)$ at a rate of $840 \pm 383$ cells per month for a total $38 \%$ loss during the time interval (Fig. 6D; Table 2). Although they were too rare to quantify, BrdU-labeled pyknotic cells were occasionally observed in brains labeled at P6 (Fig. 3).

\section{DISCUSSION BrdU dilution}

BrdU-labeled cells that continue to divide dilute their incorporated BrdU until the level in the daughter cells is too low to be detected by immunohistochemical methods, and the daughter cells "disappear." Consequently, continued generation of new cells can either add new BrdUlabeled cells, as one labeled precursor becomes two labeled daughter cells, or can, paradoxically, decrease the number of BrdU-labeled cells, when one labeled precursor becomes two unlabeled daughter cells. In the adult dentate gyrus, some daughter cells of dividing precursors continue to divide, while others become postmitotic. With each succes- sive mitosis, some of the BrdU-labeled cells are likely to disappear.

It appears that a measurable number of BrdU-labeled cells become undetectable even during the first mitosis. Because BrdU is cleared from the adult dentate gyrus within 2 hours (Cameron and McKay, 2001), the increase in the number of BrdU-labeled cells between 2 hours and 1 day after BrdU labeling likely reflects the completion of mitosis by the cells initially labeled in S-phase 22 hours earlier. The 1.7-fold increase between 2 and 24 hours is smaller than the 2 -fold increase that would be expected from the division of S-phase cells into two daughter cells during this interval but is consistent with data from a previous BrdU experiment (Cameron and McKay, 2001). A small number of BrdU-labeled pyknotic cells observed at the 24-hour time point suggests that some of the "missing" labeled cells actually died before, or shortly after, completing mitosis. However, a twofold increase was seen in a prior study using $\left[{ }^{3} \mathrm{H}\right]$ thymidine (Okano et al., 1996), suggesting that large numbers of new daughter cells do not normally die in this system. Instead, the smaller than expected increase in BrdU-labeled cells is likely to reflect some aspect of BrdU labeling itself. Significant cell death due to BrdU toxicity seems unlikely, because doubling the BrdU dose (to $600 \mathrm{mg} / \mathrm{kg}$ ) does not exacerbate this problem (Cameron and McKay, 2001). It is possible that some tightly clustered cells in the 1- to 4-day survival groups could be undercounted. However, it seems most likely that a significant proportion of BrdU-labeled cells are lost to label dilution even during this first division.

We double-labeled with BrdU and Ki-67 to address the issue of addition and dilution of BrdU-labeled cells during the first several days after injection. In the gcl, our Ki-67 data fit well with expectations based on previous studies. Nearly all $(91.4 \pm 4.9 \%)$ of the BrdU-labeled cells in the gcl expressed Ki-67 2 hours after BrdU injection, as expected if $\mathrm{Ki}-67$ is expressed by all dividing cells (Scholzen and Gerdes, 2000; Kee et al., 2002). Additionally, $50 \pm$ $6.8 \%$ of the BrdU-labeled cells in the gcl were doublelabeled at the 24-hour time point after BrdU injection, which is consistent with a steady-state model of cell division and an approximately 25-hour cell cycle (Cameron and McKay, 2001; Hayes and Nowakowski, 2002). The data in the hilus, however, were very different. Only $72 \pm$ $3.3 \%$ of BrdU-labeled cells in the hilus were Ki-67positive 2 hours after BrdU injection. Additionally, BrdU/ Ki-67 coexpression dropped very rapidly in the hilus, to only $7.0 \pm 3.1 \% 1$ day after BrdU injection and to zero by the second day. The reason for this lack of staining in BrdU-labeled hilar cells is unclear, but it could reflect weak Ki-67 expression in some mitotic populations such 

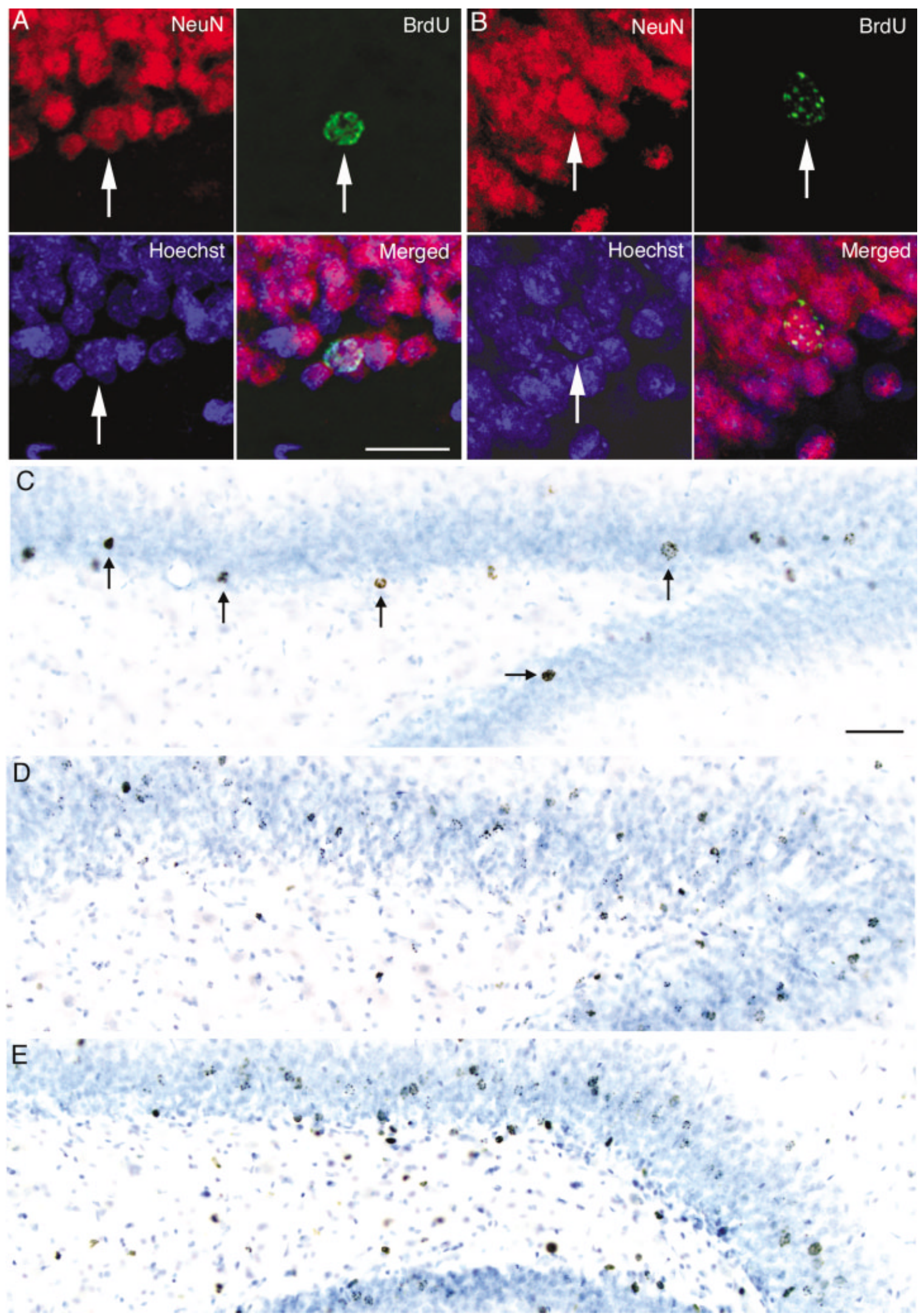

Fig. 5. Confocal (A,B) and brightfield (C-E) images of bromodeoxyuridine (BrdU) -labeled cells after 1- or 6-month survival times. A: A BrdU-labeled neuron immunoreactive for the specific neuronal marker NeuN 1 month after BrdU injection in adulthood. Projection image of four confocal planes with a total depth of $2.7 \mu \mathrm{m}$. B: A BrdU-labeled neuron immunoreactive for the specific neuronal marker NeuN 6 months after BrdU injection in adulthood. Projection image of four confocal planes with a total depth of $3.0 \mu \mathrm{m}$. C: Several BrdU-labeled cells (arrows) can be seen in the granule cell layer 6 months after a BrdU injection in adulthood (8-9 weeks of age). Even after 6 months, most of the labeled cells are still very close to the hilar border. D: Many more BrdU-labeled cells are seen in the granule cell layer and hilus 6 months after a single BrdU injection in development (postnatal day 6). Cells are scattered throughout the entire width of the granule cell layer. E: Even more BrdU-labeled cells are seen in a juvenile rat 1 month after a single BrdU injection in development (postnatal day 6). Scale bars $=20 \mu \mathrm{m}$ in A (applies to A,B), $50 \mu \mathrm{m}$ in $\mathrm{C}$ (applies to $\mathrm{C}-\mathrm{E}$ ). 

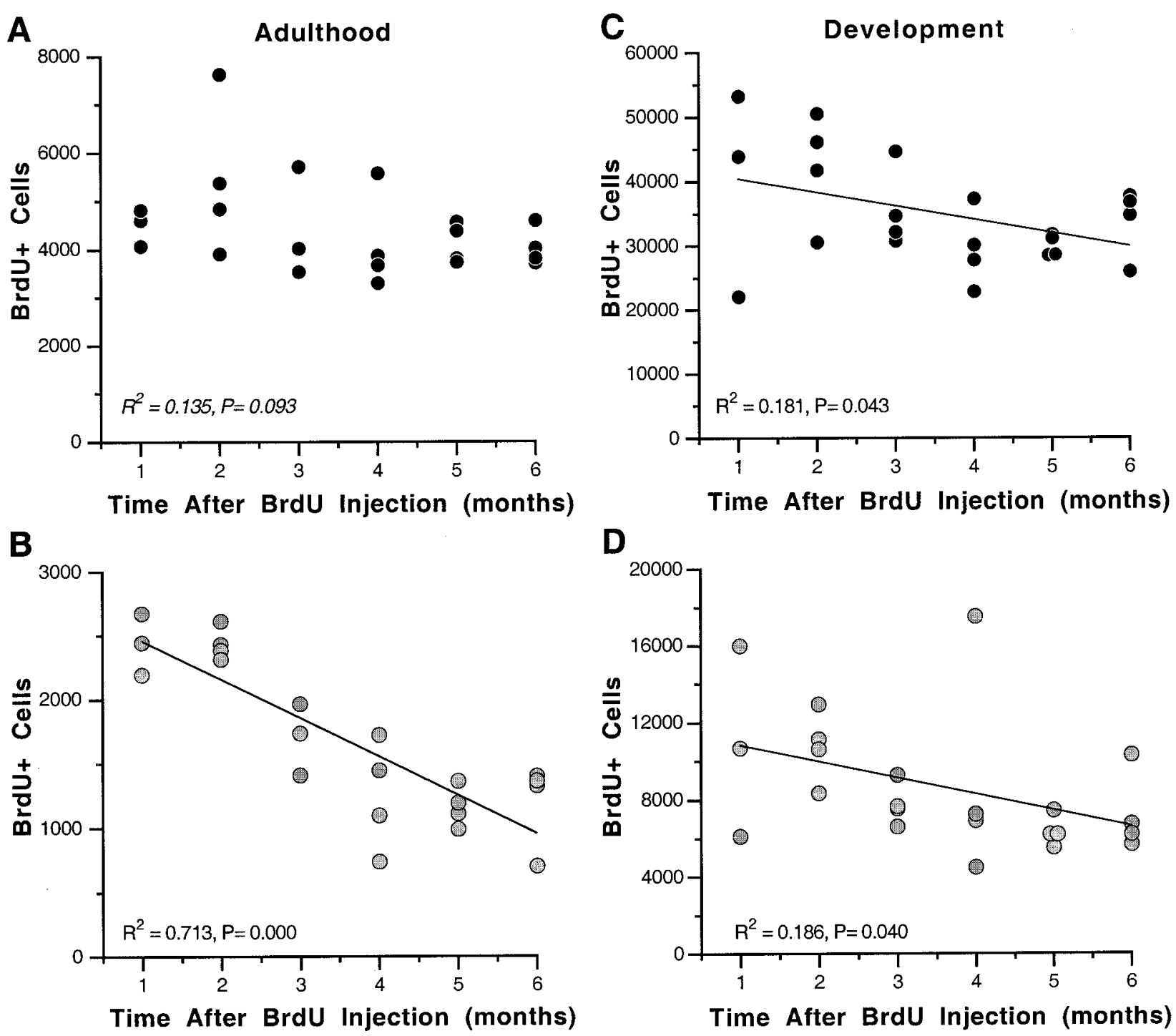

Fig. 6. Cell death stops in adult-born granule cells but continues in granule cells born during development. Graphs show the numbers of bromodeoxyuridine (BrdU) -labeled cells in individual rats, with linear regression statistics and regression lines when significant. A: In the granule cell layer, cells labeled with BrdU in adulthood show no change in number between 1 month and 6 months after BrdU

injection. Note the outlier in the 2-month group, discussed in the text. B: In the hilus, cells labeled with BrdU in adulthood show highly significant cell loss over this period. C: In rats injected with BrdU during development, significant numbers of cells are lost from the granule cell layer between 1 and 6 months after labeling. D: Cells labeled with BrdU in development are also lost from the hilus during this period.

as those in the hilus, or a much shorter S-phase and total cell cycle time in the hilar population. Whatever the reason for this unexpected data from the hilus, the gcl/ subgranular zone, where the granule cell precursors are believed to reside, showed Ki-67 staining consistent with expression in nearly all dividing cells, suggesting that the information about BrdU dilution in the granule cell precursors is reliable.

We found that some dividing (Ki-67-positive) cells were still BrdU-labeled for 4 days after BrdU injection, indicating that new BrdU-labeled daughter cells are added throughout this period of approximately four cell cycles. This is not to say that a single injection will label all cells born over a 4-day period, which it clearly will not. However, this does suggest that the "age" of a cell in the

dentate gyrus labeled with BrdU during adulthood cannot be determined more precisely than within a 4-day range. The decreasing percentage of BrdU and $\mathrm{Ki}-67$ doublelabeled cells over this period indicates that loss of BrdUlabeled cells due to dilution, in addition to gain of new BrdU-labeled daughter cells, is occurring during this period. Therefore, the essentially stable cell number between 1 and 4 days after injection suggests a balance between the gain and loss of BrdU-labeled cells. Whether or not cell death also adds to the loss of cells through label dilution over these 4 days is difficult to determine from this experiment. The observation of a very small number of possible BrdU-labeled pyknotic cells suggests that it may, although the numbers of these cells were so low that they cannot be used to provide reliable quantitative data. 
However, it is clear from this experiment, along with the lack of BrdU and Ki-67 colabeling at 8- and 16-day survival times, that any decrease in the number of BrdUlabeled cells more than 4 days after BrdU injection is very unlikely to reflect dilution of $\mathrm{BrdU}$ and, therefore, can be attributed to cell death.

\section{Identity of dying cells}

The survival rates of cells in this study changed over time and also varied across the different portions of the dentate gyrus. The current study suggests that the population of BrdU-labeled cells in the hilus is very different from the one in the gcl. BrdU-labeled cells in the hilus had a different pattern of Ki-67 expression than those in the gcl even 1 day after BrdU injection. And unlike cells in the gcl, they did not show statistical evidence of cell death between 6 and 16 days after injection but did show statistical loss between 2 and 4 months. Very little is known about the identity of newborn cells in the adult hilus during this 6-day to 6-month period. At very early time points, 1 day after 6 days of daily BrdU injections, 35\% of BrdU-labeled cells in the gcl and hilus combined have been identified previously as being endothelial, and nearly $20 \%$ appear to be glial (Palmer et al., 2000). Because cells of both types would not necessarily become postmitotic, nearly all of them may dilute their BrdU beyond the limits of detection by 6 days after BrdU injection. However, because the BrdU-labeled cells that remain in the hilus do not appear to be neurons, they are likely to be some combination of quiescent endothelial cells, glial cells, and undifferentiated progenitor or stem cells.

In the adult gcl, we found a constant and relatively high rate of death in 1- to 4-week-old cells. During this period, nearly all (94\%) of the newborn cells in the adult gcl appear to be immature neurons, based on their staining for the early neuronal marker TuJ1 (Cameron and McKay, 2001), an antibody against class III $\beta$-tubulin. Although it is impossible, because of ongoing cell birth and BrdU dilution (see above), to say exactly when cell death starts in this population, it appears to become significant around the time the cells are 1 week old. This finding is approximately the same time that the newborn granule neurons in the adult dentate gyrus probably become capable of integrating into networks, as suggested by their extension of mossy fiber axons into CA3 between 3 and 10 days after BrdU injection (Hastings and Gould, 1999). During this period of rapid cell death, hippocampusdependent behavioral tasks dramatically increase the survival of the immature granule neurons, whereas tasks that activate but do not require the hippocampus have no effect on their survival (Gould et al., 1999; Ambrogini et al., 2000). This hippocampal learning effect may also explain the increased cell survival that can be seen with "enriched" environments (Kempermann et al., 1997). These findings suggest that the immature neurons that survive an approximately 3 -week period of high susceptibility to cell death are those that become integrated into active, important circuits. Additionally, it suggests that the final number of neurons surviving from a given cohort is variable, depending on the opportunities for hippocampus-dependent learning provided by the environment over this 3 -week period. It follows from this suggestion that rats in the natural environment may retain many more neurons than rats living in the relatively im- poverished environment of standard laboratory housing, as in the current study.

Cell death in the gcl appears to stop after cells are 4 weeks old; in contrast to the rapid rate of cell death in 1to 4-week-old cells, 1- to 6-month-old cells did not die in detectable numbers. It is not clear what produces this change in susceptibility, but the timing of this change correlates well with the time that newly born neurons begin to express neuron-specific enolase (Cameron et al., 1993), a molecule that has been suggested as a marker of normal neuronal functioning (Marangos and Schmechel, 1987). A recent study has shown that 1-month-old granule neurons have also acquired several of the electrophysiological properties of mature granule cells (Song et al., 2002). Taken together, these findings suggest that the decreased susceptibility to cell death of 4-week-old cells is part of a broad array of changes that occur as neurons reach maturity.

The high rate of cell death in 1- to 2-week-old neurons has been taken previously as evidence that the granule neurons born in adulthood may be a short-lived, transient population compared with the granule cells born during development. Our data suggest that this is not the case. Both subpopulations of granule neurons undergo an early period of cell death that, at least in normal laboratory conditions, is nearly equal in magnitude; a previous study found that $40 \%$ of cells generated on P2 died within 3 weeks of labeling (Schlessinger et al., 1975), compared with $37 \%$ loss of adult generated cells over the same period in the current study. After this first month, granule cells born during development continue to slowly decline in number, losing approximately $25 \%$ more of the population within the next 5 months. In contrast, virtually all of the mature granule neurons born during adulthood live for at least 5 more months and quite possibly longer. Therefore, ongoing death of granule cells born during development appears to offset the generation of a persisting population of mature neurons during adulthood, at least to some degree. Cells born on P6 have been estimated to represent $8-9 \%$ of the total population of granule cells born during development (from E14 to P14), so the rate of death of all granule cells born in development is likely to be 11-12 times higher than what we calculated for P6 cells. However, the rate of cell death in granule cells born embryonically could be very different from that observed in granule cells generated on P6. More information is needed about the survival rate of cells born at different stages of dentate gyrus development to determine whether or not the death of developmentally born granule cells can completely compensate for the addition of new neurons in adulthood. However, loss of older granule neurons, born during development, might explain how new long-lasting granule neurons can be generated throughout adulthood without increasing the overall size of the granule cell population (Boss et al., 1985).

\section{LITERATURE CITED}

Altman J, Das GD. 1965. Autoradiographic and histological evidence of postnatal hippocampal neurogenesis in rats. J Comp Neurol 124:319335 .

Ambrogini P, Cuppini R, Cuppini C, Ciaroni S, Cecchini T, Ferri P, Sartini S, Del Grande P. 2000. Spatial learning affects immature granule cell survival in adult rat dentate gyrus. Neurosci Lett 286:21-24. 
Bayer SA. 1980a. Development of the hippocampal region in the rat. I. Neurogenesis examined with $3 \mathrm{H}$-thymidine autoradiography. J Comp Neurol 190:87-114.

Bayer SA. 1980b. Development of the hippocampal region in the rat. II. Morphogenesis during embryonic and early postnatal life. J Comp Neurol 190:115-134.

Biebl M, Cooper CM, Winkler J, Kuhn HG. 2000. Analysis of neurogenesis and programmed cell death reveals a self-renewing capacity in the adult rat brain. Neurosci Lett 291:17-20.

Boss BD, Peterson GM, Cowan WM. 1985. On the number of neurons in the dentate gyrus of the rat. Brain Res 338:144-150.

Cameron HA, McKay RD. 2001. Adult neurogenesis produces a large pool of new granule cells in the dentate gyrus. J Comp Neurol 435:406-417.

Cameron HA, Woolley CS, McEwen BS, Gould E. 1993. Differentiation of newly born neurons and glia in the dentate gyrus of the adult rat. Neuroscience 56:337-344.

Crespo D, Stanfield BB, Cowan WM. 1986. Evidence that late-generated granule cells do not simply replace earlier formed neurons in the rat dentate gyrus. Exp Brain Res 62:541-548.

Eisch AJ, Nestler EJ. 2002. To be or not to be: adult neurogenesis and psychiatry. Clin Neurosci Res 2:93-108.

Eriksson PS, Perfilieva E, Bjork-Eriksson T, Alborn AM, Nordborg C, Peterson DA, Gage FH. 1998. Neurogenesis in the adult human hippocampus. Nat Med 4:1313-1317.

Gould E, Gross CG. 2002. Neurogenesis in adult mammals: some progress and problems. J Neurosci 22:619-623.

Gould E, Woolley CS, McEwen BS. 1990. Short-term glucocorticoid manipulations affect neuronal morphology and survival in the adult dentate gyrus. Neuroscience 37:367-375.

Gould E, Woolley CS, McEwen BS. 1991. Adrenal steroids regulate postnatal development of the rat dentate gyrus: I. Effects of glucocorticoids on cell death. J Comp Neurol 313:479-485.

Gould E, Beylin A, Tanapat P, Reeves A, Shors TJ. 1999. Learning enhances adult neurogenesis in the hippocampal formation. Nat Neurosci $2: 260-265$.

Gould E, Vail N, Wagers M, Gross CG. 2001. Adult-generated hippocampal and neocortical neurons in macaques have a transient existence. Proc Natl Acad Sci U S A 98:10910-10917.

Hastings NB, Gould E. 1999. Rapid extension of axons into the CA3 region by adult-generated granule cells. J Comp Neurol 413:146-154.

Hayes NL, Nowakowski RS. 2002. Dynamics of cell proliferation in the adult dentate gyrus of two inbred strains of mice. Brain Res Dev Brain Res 134:77-85.

Kee N, Sivalingam S, Boonstra R, Wojtowicz JM. 2002. The utility of Ki-67 and BrdU as proliferative markers of adult neurogenesis. J Neurosci Methods 115:97-105.

Kempermann G, Kuhn HG, Gage FH. 1997. More hippocampal neurons in adult mice living in an enriched environment. Nature 386:493-495.

Madsen TM, Treschow A, Bengzon J, Bolwig TG, Lindvall O, Tingstrom A 2000. Increased neurogenesis in a model of electroconvulsive therapy. Biol Psychiatry 47:1043-1049.

Marangos PJ, Schmechel DE. 1987. Neuron specific enolase, a clinically useful marker for neurons and neuroendocrine cells. Annu Rev Neurosci 10:269-295.

Nakagawa S, Kim JE, Lee R, Malberg JE, Chen J, Steffen C, Zhang YJ, Nestler EJ, Duman RS. 2002. Regulation of neurogenesis in adult mouse hippocampus by cAMP and the cAMP response element-binding protein. J Neurosci 22:3673-3682.

Okano HJ, Pfaff DW, Gibbs RB. 1996. Expression of EGFR-, p75NGFR-, and PSTAIR (cdc2)-like immunoreactivity by proliferating cells in the adult rat hippocampal formation and forebrain. Dev Neurosci 18:199209.

Palmer TD, Willhoite AR, Gage FH. 2000. Vascular niche for adult hippocampal neurogenesis. J Comp Neurol 425:479-494.

Schlessinger AR, Cowan WM, Gottlieb DI. 1975. An autoradiographic study of the time of origin and the pattern of granule cell migration in the dentate gyrus of the rat. J Comp Neurol 159:149-175.

Scholzen T, Gerdes J. 2000. The Ki-67 protein: from the known and the unknown. J Cell Physiol 182:311-322.

Song HJ, Stevens CF, Gage FH. 2002. Neural stem cells from adult hippocampus develop essential properties of functional CNS neurons. Nat Neurosci 5:438-445. 